\title{
Operational network improvements and increased reporting in the NOA (Greece) seismicity catalog
}

\author{
G. Chouliaras, N. S. Melis, G. Drakatos, and K. Makropoulos \\ Institute of Geodynamics, National Observatory of Athens (NOA), 11810 Athens, Greece \\ Correspondence to: G. Chouliaras (g.choul@ noa.gr)
}

Received: 31 May 2013 - Accepted: 5 July 2013 - Published: 30 August 2013

The seismological network of the National Observatory of Athens (NOA) has systematically improved the detection capabilities in the Southeastern Mediterranean, by the continuous expansion and upgrading of the seismic stations and improvements in the operating and reporting procedures. As a result of these improvements, the number of detected events of smaller magnitudes has increased and today a homogeneous magnitude is determined and disseminated towards the scientific community.

Seismicity is generally yielded by natural earth processes while seismicity catalogs are produced by the standard seismological practice and network operating procedures of the reporting center. Seismicity catalogs provide valuable information concerning the tectonic processes in seismically active regions and they are a cornerstone for the determination of seismic hazard. It is well known that seismological network changes such as: new station installations or station closures, instrumentation upgrades, data analysis procedures, magnitude definition and station averaging techniques, are important factors that may create artifacts in seismicity catalogs and thus conceal the real ongoing earth processes. On the other hand, the quantitative analysis of seismicity catalogs may provide valuable insight to network operators for the designing and structuring of their operational seismological network (Thormann et al., 2010).

In 1964, the first WWSN seismic station was established in Greece and the seismological network of NOA initiated the uninterrupted production and dissemination of an instrumental earthquake catalog. The catalog is updated every daily by the 24/7 operational observatory practice in which a geophysicist analyses the real-time determination of parametric information and determines the final parametric solution which is archived in http://www.gein.noa.gr. This detailed earthquake catalog spans the last half century and reports parametric data for more than 140000 events, has been used in a plethora of investigations that concern the seismicity, seismic hazard and risk analysis of the region. After 2011, the seismological network expansion in Greece was achieved by the unification of the seismological network of NOA with the seismological networks of the Universities of Athens, Thessaloniki and Patras, thus forming the Hellenic Unified Seismological Network (HUSN) consisting of more than 140 reporting stations (http://www.gein.noa.gr/en/networks/husn). The threefold increase in the number of reporting stations, significantly improved the detection ability of the network for the larger part of the Greek region and this has resulted in a spatial and temporal variation in the magnitude of completeness $\left(M_{\mathrm{c}}\right)$. It should be pointed out that the observatory practice at NOA produces catalog updates daily from the preliminary measurements with a time lag of one day, while real time seismicity listing is always available.

The $M_{\mathrm{c}}$ is a significant parameter for network operators as well as to scientists involved in seismic hazard and earthquake prediction research (Chouliaras et al., 2012, 2013; Sarlis et al., 2008; Varotsos et al., 2002). Changes in the $M_{\mathrm{c}}$ due to artificial seismicity rates (ASR) result from changes in the network operating and reporting procedures, which must be identified and excluded in order to unmask the real earth processes (Zuninga and Weimer, 1999). Recent seismicity rate increases, due to the additional installation of seismological stations and improvements in the analysis and reporting for the HUSN network, have been documented locally for the Santorini and the Southwestern Peoponessus seismic swarms by Chouliaras et al. (2012, 2013). In this investigation we continue the above research and determine the spatial variability of the $M_{\mathrm{c}}$ for the entire Greek region, using the NOA seismicity catalog. 


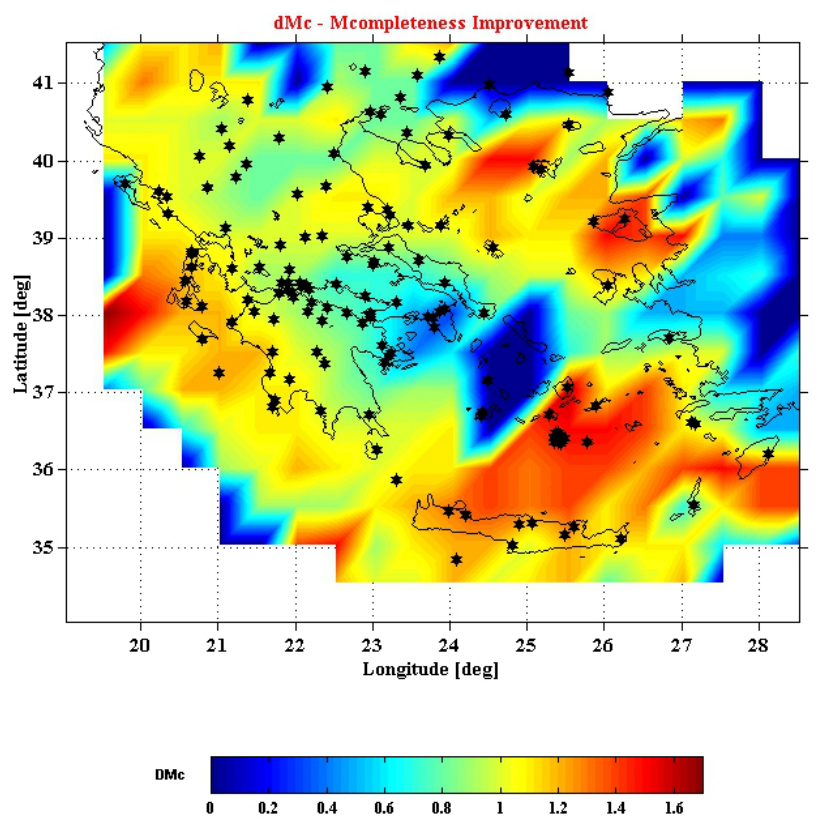

Fig. 1. $M_{\mathrm{c}}$ difference map $\left(\mathrm{d} M_{\mathrm{c}}\right)$ determined by quantitative analysis of the frequency-magnitude distribution (FMD) at a constant grid spacing for two time periods 1964 until 2011 and 2011 until 2013. Asterisks indicate seismological stations.

Figure 1 is the $M_{\mathrm{c}}$ difference map $\left(\mathrm{d} M_{\mathrm{c}}\right)$ determined by quantitative analysis of the frequency-magnitude distribution (FMD) at a constant grid spacing for two time periods 1964 until 2011 and 2011 until 2013, namely the background and foreground periods, respectively (i.e. before and after the expansion of the seismological network in 2011). This result indicates an overall improvement in the detection of the seismic activity as $M_{\mathrm{c}}$ is observed to decrease (yellow-red shaded areas) by up to 1.5 magnitude units in the foreground period. The most significant improvement in the detection ability is found in the areas of Santorini, Crete, Ionian and Northeastern Aegean, islands, where we have additional new reporting in the NOA seismicity catalog after 2011 due to the operation of the HUSN network. In contrast to this, no major change in $M_{\mathrm{c}}$ is observed for the region around Central Greece, since the seismological network had already been expanded in this area prior to the 2004 Olympic Games in Athens.

In Fig. 2 we present the cumulative and non-cumulative seismicity rate distributions for the periods 1964 until 2011 (background period-red) and 2011 until 2013 (foreground period-blue). The comparison indicates a significant rate increase for the foreground period by more than $750 \%$ for earthquakes with magnitudes less than $M_{\mathrm{c}} \sim 3$. This significant rate increase peaks at $M_{\mathrm{c}} \sim 1.5$ after 2011 and the clear shift of $M_{\mathrm{c}}$ by 1.5 magnitude units corresponds to the $\mathrm{d} M_{\mathrm{c}}$ variation ( 0 to 1.5 magnitude units) in the corresponding spatial variation map of Greece.
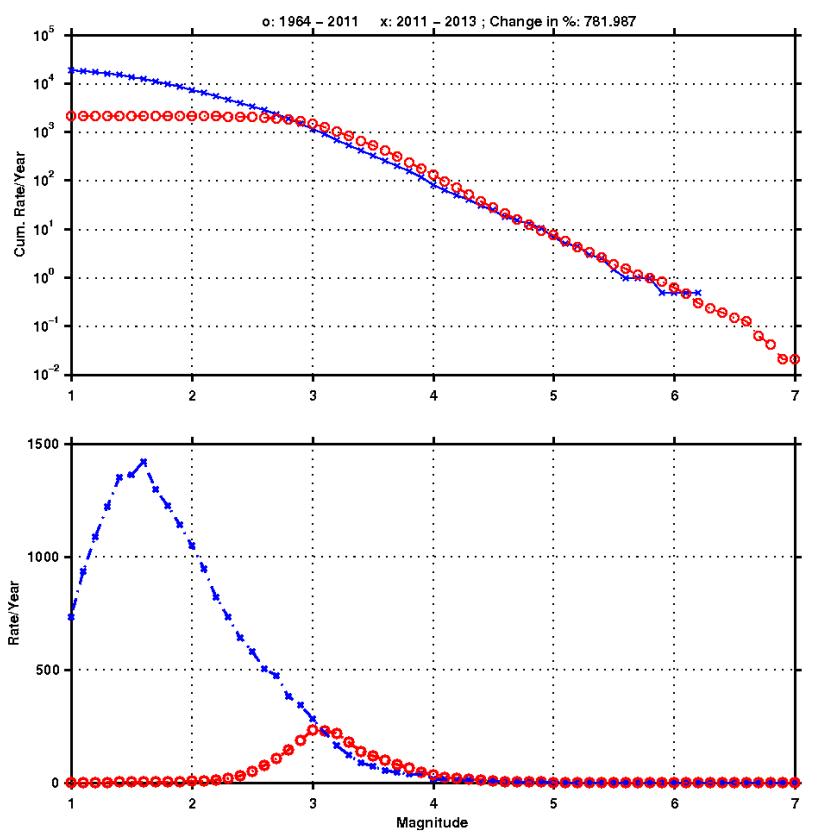

Fig. 2. Cumulative and non-cumulative seismicity rate distributions for the periods 1964 until 2011 (background period-red) and 2011 until 2013 (foreground period-blue).

Magnitude shift, magnitude stretch and seismicity rate constants are also quantified in this study using the FMD fitting method of Zuninga and Wyss (1995). Figure 3 presents results of this methodology which determines a best fit model from the residuals of the difference between the observed (magenta) and synthetic (green) background periods. The synthetic FMD is determined from the foreground FMD (blue curve) by either a linear transformation of the form $M_{\text {new }}=M_{\text {old }}+d$ with $d=-0.3$ or a band-dependant transformation of the form $M_{\text {new }}=c \cdot M_{\text {old }}+d$, using the determined constants and the corresponding rate factor.

We conclude that a significant rate change in the NOA sesmicity catalog has been identified to coincide with the seismological network expansion period in Greece and the establishment of the HUSN database after 2011. The routine monitoring of the seismicity rate with the methodology employed in this study is suggested in order to identify and correct for any changes in the detection ability of operational seismological networks.

Acknowledgements. The authors would like to thank both reviewers and the editor for constructive comments. This research was partly financed by the XENIOS Project $(096 \Sigma \mathrm{YN}-31-867)$, coordinated by the Greek Ministry of Research and Technology, the Laboratory of Climatology and Atmospheric Environment (LACAE) of the Faculty of Geology and Geoenvironment, National and Kapodistrian University of Athens and by the EPOS - PP project (Grant Agreement No. 262229). The encouraging support of the UNESCO 


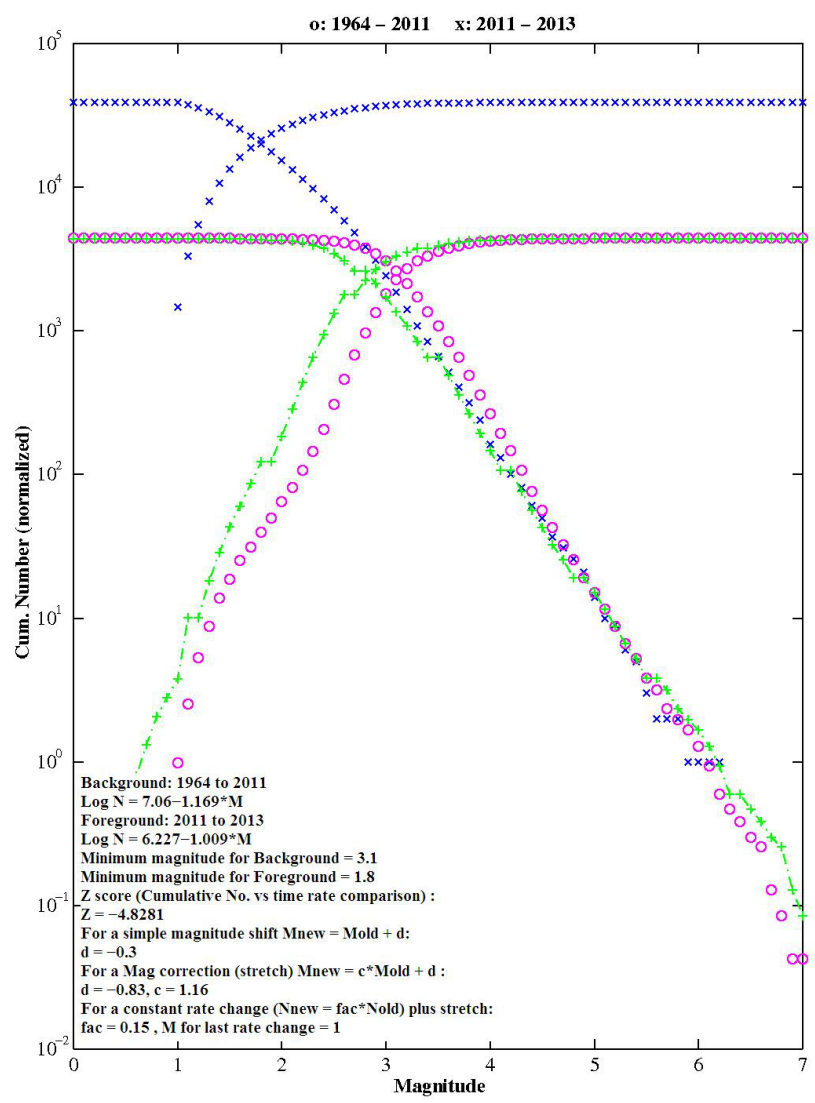

Fig. 3. FMD fitting method. A best fit model from the residuals of the difference between the observed (magenta) and synthetic (green) background periods.
Chair on Natural Hazards at the National Observatory of Athens is greatly appreciated.

\section{References}

Chouliaras, G., Drakatos, G., Makropoulos, K., and Melis, N. S.: Recent seismicity detection increase in the Santorini volcanic island complex, Nat. Hazards Earth Syst. Sci., 12, 859-866, doi:10.5194/nhess-12-859-2012, 2012.

Chouliaras, G., Drakatos, G., Pavlou, K., and Makropoulos, K.: Stress distribution and seismicity patterns of the 2011 seismic swarm in the Messinia basin, (South-Western Peloponnesus), Greece, Nat. Hazards Earth Syst. Sci., 13, 45-51, doi:10.5194/nhess-13-45-2013, 2013.

Sarlis, N. V., Skordas, E. S., Lazaridou, M. S., and Varotsos, P. A.: Investigation of the seismicity after the initiation of a Seismic Electric Signal activity until the main shock, Proceedings of the Japan Academy, Ser. B, 84, 331-343, 2008.

Thormann, T., Wiemer, S., and Hauksson, E.: Changes of reporting rates in the Southern Californian earthquake catalog, introduced by a new definition of ML, B. Seismol. Soc. Am., 100, 17331742, 2010.

Varotsos, P. A., Sarlis, N. V., and Skordas, E. S.: Long-range correlations in the electric signals that precede rupture, Phys. Rev. E, 66, 1-7, 011902, 2002.

Zuninga, F. R. and Wyss, M.: Inadvertent changes in magnitude reported in earthquake catalogues: influence on b-value estimates, B. Seismol. Soc. Am., 85, 1858-1866, 1995.

Zuninga, F. R. and Wiemer. S.: Seismicity patterns: are they always related to natural causes?, Pure Appl. Geophys., 155, 713-726, 1999. 